\title{
ASPECTOS DERMATOLÓGICOS DA TOXOPLASMOSE *
}

\author{
Vicente Amato Neto **
}

\begin{abstract}
São efetuadas considerações sôbre manifestaçôes cutâneas encontrảveis em pacientes com toxoplasmose adquirida.

Fundamentalmente, foram verificadas as seguintes alterações: a) erupção máculo-papular petequial; b) alteração máculo-papular; c) erupção vesiculosa: d) erupção escarlatiniforme; el eritema nodoso; f) erupçâo de caráter misto.

o assunto mereceu comentários sobretudo som a finalidade de ser apresentada uma sistematização inicial, tendo ficado salientado aue a toxoplasmose oferece aos dermatologistas, sem duivida, motivos justificadores de cabais interêsse e atenção.
\end{abstract}

A toxoplasmose, em virtude dos múltiplos tipos de acometimento orgânico que pode determinar, merece interêsse por parte dos médicos que se dedicam a várias especialidades. Isso é o que sucede especialmente em relação a pediatras, neonatalistas, oftalmologistas, neurologistas e obstetras, assim como aos que executam tarefas clínicas de caráter geral ou ligadas mais especialmente às doenças transmissiveis. Além disso, outros profissionais, tais como veterinários e epidemiologistas têm motivos para preocupar-se com problemas referentes a essa protozoose.

Sob o ponto de vista clínico, além dos comprometimentos correspondentes à modalidade congênita da infecção, cutros podem ter lugar, compondo as facêtas relativas às formas adquiridas. Considerando as informaçóes consignadas na literatura médica e as observaçōes que pudemos realizar, a toxoplasmose adquirida é capaz de causar as agressões a seguir especificadas, presentes isoladamente ou em assciações variáveis: a) miocardite; b/ hepatite; c) pneumonia em geral de caráter interstical; d) erupção cutânea; el meningoencefalite; f) coriorrtinite; g) miosite; $h$ ) afecções de natureza linfoglandular. O último tipo mencionado é realmente o único que permite suspeita diagnóstica concreta, uma vez que os demais processos orgânicos são confundíveis com muitos outros, atribuíveis às mais diversas etiologias, devendo a correta diferenciação depender de apropriada conduta clínica e dependente dos resultados de exames subsidiários. É preciso salientar também que a infercão toxoplasmótica é considerada assintomática em relação a múl-

Trabohio do Serviço de Doenças Transmissiveis, do Hosuiral do Servidur Público Estadual "Francisco Morato de Oliveira", de São Faulo. Apresentado no Seminário do Instituto de Medicina Tropical de São Paulo realizado no dia 18 de abril de 1968.

* Médico-chefe do Servico de Doenças Transmissiveis, do Hospital do Servidor Público Estadual "Fran. cisco Morato de Oliveira", de Sāo Paulo. Livre-docente de Clinica de Doenças Tropicais e Infectuosas. da Faculdade de Medicina da Universidade de Säo Paulo. Profescor de Doençs Transmissíteis, da Faculdade de Ciências Médicas da Universidade Estadual de Campinas.

Recebido para publicação em 10-6-70. 
tiplos casos e essa circunstância torna necessário interpretar judiciosamente diferentes situações clínicas, uma vez que a positividade de provas laboratoriais pertinentes à infecção devida ao Toxoplasma gondii, nessas eventualidades, não é suficiente para o final esclarecimento das situações vigentes. Informações mais detalhadas sôbre êsses aspectos estão assinaladas no manual especializado, de autoria de Amato Neto \& Campos (1)

A toxoplasmose é doença que sỏmente nos últimos anos passou a ser alvo de mais intensivas e numerosas apreciações, das quais resultaram novas e importantes verificações; mesmo assim, entretanto, é fácil compreender que outras facêtas paulatinamente venham a ser reveladas. Por exemplo, Spilborghs \& Federico (4), em São Paulo, chamaram a atenção para a possivel existência de uma forma reumática da toxoplasmose. no decurso da qual participação articular é notória; sôbre o assunto, no entanto, informações mais decisivas deverão levar a uma conclusão definitiva. Após têrmos observado, inclusive evolutivamente, muitos casos da modalidade adquirida da protozoose, percebemos que alteraçōes cutâneas não são excepcionais e apresentam-se segundo expressões variáveis, dignas de uma consideração global, que pode eventualmente envolver alguns méritos fundamentais, representados pelo interêsse prático da questão, pela concretização de uma sistematização inicial capaz de suscitar aprimoramentos futuros e pela indicação de lesões cuja relacão causal com a infecção precisa ser alvo de confirmação por parte de outros pesquisadores, em relação às respectivas naturezas e freqüências.

De maneira sucinta, os acometimentos cutâneos, relativos à toxoplasmose adquirida, segundo as apreciações que pudemos realizar, ocorrem de acôrdo com os tipos a seguir mencionados.

a) Erupção máculo-papular petequial. - É semelhante à presente em pacientes com riquetioses, motivando confusão com febre maculosa. Não nos parece comum e sôbre ela Meira \& cols. (2) efetuaram comentários mais minuciosos, salientando especialmente os detalhes fornecidos por Finkerton e Henderson (3). b) Erupção máculo-papular. - Foi a mais habitual entre os pacientes por nós considerados. Difusa ou localizada, geralmente está presente no tórax e tem duração variável; porém, muitas vêzes é fugaz e pode ser responsável por descamação.

Esta forma de erupção é causa de confusões com sarampo e rubéola e sòmente análises clínicas cuidadosas, em algumas oportunidades amparadas pelos resultados de exames subsidiários, possibilitam concretas diferenciaçōes. Lembramos que a conjuntivite, o enfartamento ganglionar e a plasmocitose verificável em estádios iniciais, notados em alguns indivíduos com toxoplasmose, permitem ainda mais a ocorrência de dificuldades.

E conveniente destacar que a infecção devida ao Toxoplasma gondii manifestase, em certas ocasioes, sob a forma de surtos, circunstância que põe ainda mais em foco a oportunidade de confusão com doenças exantemáticas. Por exemplo, em uma escola de São Paulo, conforme tomamos conhecimento, vários jovens apresentaram quase que concomitantemente erupção máculo-papular e rubeóla foi a dcença considerada como determinante da situação; alguns meses após, porque algumas dessas pessoas ainda tinham enfartamento de gângilos superficiais e nossa opinião foi solicitada, verificamos que seis estudantes, entre dez clínica e laboratorialmente examinados, apresentavam, sem dúvida, toxoplasmose. Curiosamente, então, a propósito dessa occrrència de casos em épocas bem próximas, em um mesmo ambiente, a manifestação exantemática surgiu como sinal comum e bastante expressivo.

A alteração máculo-papular, se não houver cuidadosa interpretação, permitirá ainda outras confusões, entre as quais destacamos as com mononucleose infecciosa e febre tifóide, sendo que diversos elementos clínicos comuns a tôdas essas infecçōes geram sempre a existência de dificuldades suplementares. A citada doenca salmonelótica foi por nós lembrada porque ela pode motivar a presença das conhecidas roseólas e também em virtude da reação de Widal mostrar-se positiva en alguns casos de toxoplasmose, conforme temos verificado e documentaremos 
em publicação específica sôbre a questão, fornecendo cs necessários detalhes.

Quanto à erupção máculo-papular salientamos, finalmente, que ela é fugaz ou, pelo contrário, mais persistente, ficanclo nctada, às vêzes, durante período prolongado. Por outro lado, certos doentes apresentam-na de maneira recurrente, surgindo as modificacóes da pele em uma ou mais oportunidades.

c) Empnác vesiculosa. - E variceliforme, mas alguns dosntes são acometidos de lesōes maiores, claramente bolhosas. Em geral, globalmente, não há exuberância habitualmente nerceptível em casos de varicala, estando presente um número limitado de elementos eruptivos.

a) Erupçẽo escarlatinifonno. - Merece seguramente essa qualificacăo. mas não tem sido encontrada, por nos, com freqüência.

e) Erilerna ncdoso. - Fol detentado não comumente, em concomitâneia com vários sinais e sintomas cecorrentes da infecção toxoplasmótica adruirida e aguda.

f) Erupeão de caráter misto. - Engloba, a um só tempo, algumas das anormalidades anteriomente referdes. Na realidade, foi verificada en puquissimas crasiões.

Complementando essa relação de acometimentos dematologicos, consideramos judicioso e cportuno registrar mais algumas impressões concernentes às lesōes constatáveis na pele de individuos com toxoplasmose adquirida. Antes, porém, destacamos que cm criancos com a forma congênita de infecça altoraços cutaneas são também perceptiveis, se bem que de maneira não sistematica; são elas máculopapulares, petequiais ou até mesmo hemorragicas e fatores diferentes foram indirados como carazes de explicá-las: fenômenos embólicos, reaṣoes toxicas, hipoproteinemia e trombonitopenia. Entretanto, como iniciamente referimos, na presente comunicação apenas daremos ênfase aos aspectos dermatológicos relativos à toxoplasmose adquirica.

As lesões dematolugicas geralmente apresentam-se associadas a outras alteracões orgânicas e não estamos em condiçoes de afirmar se, na verdade, existem cascs com acometimento exantemático puro ou predominante.

Apesar de comprometimento cutâneo fazer parte, com rełativa freqüencia, do decurso clínico da toxoplasmose adquirida, é conveniente salientar que ela não é pròpriamente uma doença exantemática, ao ser encarada com rigor esta denominação. Trata-se, realmente, de aferção que as vêzes desencadeia o aparecimento de lesóes ao nivel da pele, como yárias outras, tais como as viroses causadas por vírus FCHO e Coxsackie, a mononuleose infezcicsa, a influenza, a febre tifóide, a brucelose e a leptospirose, por exemplo.

E. evidentemente possivel que fatores independentes da toxoplasmose tenham influido no sentido de determinar o aparerimento. em alguns casos, das lesões mençcnadas. Não realizamcs sistemàticamente avaliaços destinadas a excluí-los, mas o licito subor que essas eventuais interferencias pcsam ter ocorrido apenas de mareira esporádica e não regular. Mesmo em fece a exesucào de exames complementares apropriados temos a certeza de que icplasmose continuaria a constituir entidade sufirientemente capaz do explicar a srande gorelaldade dos distúrbios cutâneos por nós anteriormente referidos. Admitimos inclusive aue o uso de drogas e conelatas reacoes de hipersensibilidade tenhom partioipado da gênese de algumas das altevaçōes da pale já comentadas mas, a respeito, consideramos válida a apreciacão pruco antes registraca, ou reja. a de uve clobalmente não sofreria modificação o panorama que tivemos a intenção de descrever.

Alguns problemas precisarão ser mehor resolvidos futuramente, quanto aos aspectos dermatológicos da toxoplasmose; entre des, ancreliamos a oportunidade para destacar os seguintes: a) a freqüencia com que se manifeston as lesões cutâneas; b) cs mecanismos segundo os quais clas são desencadeadas; c) a possibilidade de serem assas aiteracóes mais ou manoz comuns de acôrdo ccm as diferentes áreas secgréficas.

Apresentando estas considerações, tivemos spenas a intencão de chamar a atencão para aspectos pertinentes à toxoplasmose que nos pareceran dignos de uma 
tentativa de sistematização inicial. Certamente, à base de novos subsídios que serão referidos por diversos pesquisadores, a questão sofrerá indiscutível aprimoramen- to. De qualquer forma, porém, parece-nos que a toxoplasmose oferece aos dermatologistas, sem dúvida, motivos justificadores de cabais interêsse e atenção.

\section{SUMMARY}

The skin manifestations of patients with acquired toxoplasmosis were discussed.

The alterations observed consisted fundamentally of: a) petechial maculopapular eruption; b) maculopapular eruption; c) vesiculate eruption; d) scarlatiniforme eruption; e) nodular erythema; f) mixed eruption.

Comments are called for, chiefly with the purpose attempt systematization since, as has been stressed, toxoplasmosis is for dermatologist, surely and for obvious reasons, a matter of great interest and attention.

\section{BIBLIOGRAFIA}

1. AMATO NETO, V. \& CAMPOS, R. Toxoplasmose. São Paulo, Livraria Atheneu Editôra São Paulo S. A., 1965, $102 \mathrm{pp}$.

2. MEIRA, J. A., NÓBREGA, P. \& AMATO NETO, V. - Toxoplasmose adquirida (forma febril exantemática). Considerações clínicas sôbre um caso observado em adulto e diagnosticado pelas provas sorológicas. Efeito terapêtico do cloranfenicol. Rev. Hosp Clin. Fac. Med. S. Paulo, 7: 263$290,1952$.
3. PINKERTON, H. \& HENDERSON, R. G. - Adult toxoplasmosis. A previously unrecognized disease entity simulating the typhus-spotted fever group. J.A.M.A., 116: 807-814, 1941.

4. SPILBORGHS, G. \& FEDERICO, W. A. - Toxoplasmose articular. Apresentado no VI Congresso Brasileiro de Reumatologia, realizado em São Paulo, Brasil, em julho de 1966. 